\title{
The effects of velvet antler polypeptides on the phenotype and related biological indicators of osteoarthritic rabbit chondrocytes
}

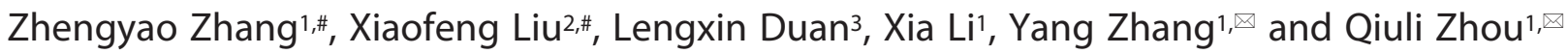 \\ 'Department of Biopharmacy, School of Pharmaceutical Sciences, Jilin University, Jilin, P.R. China; ${ }^{2}$ Clinical Laboratory of Tumor Hospital of Jilin \\ Province, Jilin, P.R.China; ${ }^{3}$ Department of Pharmacology, Henan University of Science and Technology, Henan, P.R. China
}

Objective: To study the effects of velvet antler polypeptides (VAPs) on osteoarthritic chondrocytes (OCs) in rabbits. Methods: An osteoarthritic rabbit model was established according to Hulth's method. OCs were isolated and cultured for observation of the cell cycle. Cell proliferation was detected by MTT assay and the cell cycle was monitored by flow cytometry. The phenotype was determined by toluidine blue staining as well as immunohistochemical staining for collagen type II. The expression of MMP-1, MMP-3, MMP-13, TIMP-1, and collagen I and X mRNA by chondrocytes was assayed by RT-PCR. Results: The VAPs had no obvious proliferative effect on OCs and did not affect the cell cycle. However, they significantly reduced the proportion of early apoptotic cells in a dose-dependent manner. Further, VAPs inhibited the expression of collagen $I$ and $X$ mRNA and induced abnormal expression of MMP-1 and MMP-13 mRNA. VAPs had no significant effect on MMP-3 and TIMP-1 mRNA levels. The toluidine blue and collagen type II immunohistochemical staining intensities of VAPtreated chondrocytes were positively correlated with the concentration of VAPs used. Conclusion: VAPs had no significant effect on $\mathrm{OC}$ proliferation and the cell cycle, but did increase the glycosaminoglycan (GAG) and collagen type II expression levels in the extracellular matrix, and down-regulated collagen I and X mRNA expression. Treatment of cartilage cells with VAPs maintained their normal phenotype, inhibited matrix metalloproteinases (MMPs) secretion, kept the balance of cartilage matrix metabolism, and sustained an external environment where the cartilage cells could survive. Moreover, VAPs reduced the proportion of early apoptotic cells, suggesting that they may block the apoptotic pathway in OCs.

Keywords: velvet antler polypeptides, osteoarthritic chondrocytes, apoptosis, MMP

Received: 11 November, 2010; revised: 12 May, 2011; accepted: 03 July, 2011; available on-line: 11 July, 2011

\section{INTRODUCTION}

Velvet antlers have several pharmacological properties and have been used in the clinical treatment of many diseases. Velvet antler polypeptides (VAPs) (have been found to regulate immune activities and have anti-oxidant properties (Kim et al., 2003). Studies have shown that osteoarthritis can be effectively treated with VAPs (Kim et al., 2005; 2008). Another study has also shown that the incidence of osteoarthritis is closely related to the pathology of chondrocytes (Kraan et al., 2009). In addition, it has been reported that VAPs have an effect on the proliferation of normal cartilage cells in rabbits (Guo et al., 1998; Qu \& Kang, 2000). In this study, we investigated the effects of VAPs on osteoarthritic chondrocytes (OCs) to clarify the pathogenesis of osteoarthritis and to provide an experimental basis for the clinical application of VAPs.

\section{MATERIALS AND METHODS}

Experimental animals. The Laboratory Animal Center of Bethune Medical College of Jilin University (Certificate of Quality No. 0024449) provided 24 Japanese, big-ear white rabbits that were 5 months old (12 males and 12 females) and $2.0-2.5 \mathrm{~kg}$ in weight.

Reagents. Our research group purified VAPs (Duan, 2007) and commercially obtained the following reagents: MTTT (Amresco Inc., USA), Cell Apoptosis PI Detection Kit (KeyGEN, China), Annexin V-FITC Apoptosis Detection Kit (KeyGEN), toluidine blue, 1,9-dimethyl methylene blue, and type II collagenase (Sigma-Aldrich, USA), collagen II antibody (Neomarkers Inc., USA), SP and $\mathrm{DAB}$ kits (Maixin, China), reverse transcription kit (MBI Inc., USA), Taq and the DL2000 marker (Takara, Japan), IMDM (Gibco, USA), FBS (HyClone Inc., USA), trypsin (Dingguo, China), and dimethyl sulfoxide (DMSO) (Beijing Chemical Plant, China).

Instruments. The following instruments were used in this study: an automatic microplate reader (TECAN, Austria), $\mathrm{CO}_{2}$ incubator (Thermo Scientific 3110, USA), flow cytometer (BD Biosciences, USA), optical microscope (Olympus PM2, Japan), inverted microscope (CK type, Olympus), spectrophotometer (Ascent, China), constant temperature water bath (Yiheng Experimental Instrument Co., Ltd., China), and Image-Pro image analysis software (http://www.mediacy.com/index. aspx?page=Image_Pro_Software).

Establishment of osteoarthritis model in rabbits and isolation and culturing of chondrocytes. The

e-mail: qiulizhoujl@yahoo.com.cn

e-mail:zyang@jlu.edu.cn

\#These two authors contributed equally to this work.

Abbreviations: DEPC, diethylpyrocarbonate; $\mathrm{ddH}_{2} \mathrm{O}$, double-distilled water; DMSO, dimethyl sulfoxide; GAG, glycosaminoglycan; IMDM, Iscove's modified Dulbecco's medium; MTT, 3-(4,5-dimethyl2-thiazolyl)-2,5-diphenyl-2H-tetrazolium bromide; MMPs, matrix metalloproteinases; OCs, osteoarthritic chondrocytes; TIMP, tissue inhibitor of metalloproteinase; RT-PCR, reverse transcriptionpolymerase chain reaction; $\mathrm{PI}$, propidium iodide; VAPs, velvet antler polypeptides. 
24 rabbits were divided into 8 groups of 3 rabbits each. One rabbit from each group underwent a sham operation, and the other 2 were used for the osteoarthritis model, according to the method by Hulth et al. (Liu et al., 2005). One group of models was created every week for 8 weeks. On the 9 th week and thereafter, one group of animals was selected for the isolation and culturing of chondrocytes every week.

To isolate chondrocytes, the knee of each rabbit was isolated, rinsed, and immersed in sterile D-Hank's solution. The articular cartilage was then isolated from the patellar and collateral ligaments, rinsed, and ground to $1 \mathrm{~mm}^{2}$ sections in D-Hank's solution. The tissue was then digested with $0.25 \%$ trypsin containing $0.04 \%$ EDTA and incubated at $37^{\circ} \mathrm{C}$ for $30 \mathrm{~min}$. The trypsin was then removed and Type II collagen was added. The cells were finally incubated at $37^{\circ} \mathrm{C}$ for $4 \mathrm{~h}$, filtered, and centrifuged. Iscove's modified Dulbecco's medium (IMDM) containing 10\% FBS (fetal bovine serum) was used for cell culture. After cell adherence, different concentrations of VAPs $(6.25,12.5$, and $25.0 \mu \mathrm{g} / \mathrm{mL})$ were added to the culture medium, and the related biological markers were examined for the next 8 weeks. The following cell groups were established: a control group, for which cells were isolated from the sham-operated rabbits and cultured in media alone; a model group, for which cells were isolated from the osteoarthritic rabbit model group and cultured in media; a low-dose VAP group, for which $6.25 \mu \mathrm{g} / \mathrm{mL}$ of VAPs was added to the cells from the model group during culture; a moderate-dose VAP group, for which $12.5 \mu \mathrm{g} / \mathrm{mL}$ of VAPs was added; and a high-dose VAP group, for which $25 \mu \mathrm{g} / \mathrm{mL}$ of VAPs was added.

Determination of proliferation by the MTT assay. For the MT'T assay, $5 \times 10^{4} / \mathrm{mL}$ chondrocytes were seeded in 96-well plates, with each well containing $0.1 \mathrm{~mL}$ of the cell suspension. After cell adherence, $0.2 \mathrm{~mL}$ of VAPs was added to each well and the cells were cultured for $48 \mathrm{~h}$, MTT $^{\prime}(5 \mathrm{mg} / \mathrm{mL}$ ) was added to each well. After $4 \mathrm{~h}$ of incubation, the medium was removed and 100 $\mu \mathrm{L}$ DMSO was added to resuspend the MTT metabolic product. The absorbance was measured at $570 \mathrm{~nm}$.

Cell cycle analysis by flow cytometry. Four $\mathrm{mL}$ of $5 \times 10^{4} / \mathrm{mL}$ chondrocytes from each group were seeded in $25 \mathrm{~cm}^{2}$ culture flasks. After cell adherence, $1 \mathrm{~mL}$ of VAPs was added to each flask and the cells were cultured for $48 \mathrm{~h}$. The cells were then digested with $0.25 \%$ trypsin, collected, and fixed with $70 \%$ ice-cold ethanol for PI single staining. Flow cytometry was used to detect changes in the cell cycle.

Detection of glycosaminoglycans (GAG) and collagen type II in chondrocytes. In order to culture cells on coverslips, $5 \times 10^{4} / \mathrm{mL}$ chondrocytes from each group of cell seeded in 6-well plates with a single coverslip placed in each well. Each well received $2 \mathrm{~mL}$ suspension. After cell adherence, $1 \mathrm{~mL}$ of VAPs was added to each well and the cells were cultured for $48 \mathrm{~h}$. The cells were then fixed with $4 \%$ paraformaldehyde for (1) determination of the phenotype by toluidine blue staining and (2) immunohistochemical staining of collagen type II.

Detection of the expression of MMP-1, MMP-3, MMP-13, TIMP-1, and collagen $I$ and $X$ mRNA in chondrocytes. Four $\mathrm{mL}$ of $5 \times 10^{4} / \mathrm{mL}$ chondrocytes from each group were seeded in $25 \mathrm{~cm}^{2}$ culture flasks. After cell adherence, $1 \mathrm{~mL}$ of VAPs was added into each flask and the cells were cultured for $48 \mathrm{~h}$.

Total RNA was extracted with Trizol reagent (Invitrogen) and cDNA was synthesized by RT-PCR. The prim-
Table 1. Effects of VAPs on OC proliferation $(n=6)$

\begin{tabular}{lc}
\hline Group & $A_{570}$ \\
\hline Control & $0.540 \pm 0.024$ \\
Model & $0.594 \pm 0.040^{*}$ \\
$6.25 \mu \mathrm{g} / \mathrm{mL}$ VAPs & $0.604 \pm 0.035$ \\
$12.5 \mu \mathrm{g} / \mathrm{mL}$ VAPs & $0.609 \pm 0.043$ \\
$25.0 \mu \mathrm{g} / \mathrm{mL}$ VAPs & $0.625 \pm 0.044$ \\
\hline
\end{tabular}

Note: ${ }^{*} P<0.05$ vs. control

ers used are listed in Table 4. Briefly, $1 \mu \mathrm{g}$ RNA, $1 \mu \mathrm{l}$ oligo(dT), and $0.1 \% \mathrm{DEPC} \mathrm{ddH}_{2} \mathrm{O}$ to a final volume of $12 \mu \mathrm{l}$ were mixed and incubated at $70^{\circ} \mathrm{C}$ for $5 \mathrm{~min}$. The sample was then immediately placed on ice and vortexed after being cooled. After vortexing, $4 \mu \mathrm{l} 5 \times$ reaction buffer, $1 \mu \mathrm{l}$ RNA inhibitor, and $2 \mu \mathrm{l}$ of a dNTP mixture were added and incubated at $37^{\circ} \mathrm{C}$ for $5 \mathrm{~min}$. One microliter of reverse transcriptase was then added and the total reaction volume was $20 \mu \mathrm{l}$. For RT-PCR, the sample was incubated at $42^{\circ} \mathrm{C}$ for $60 \mathrm{~min}$ followed by $70^{\circ} \mathrm{C}$ for $10 \mathrm{~min}$ to inactivate reverse transcriptase, and then placed on ice. The following PCR conditions were then used: $2 \mu \mathrm{l} 10 \times$ Taq buffer, $2 \mu \mathrm{l}$ dNTP, $1 \mu \mathrm{l}$ of each primer, $1 \mu \mathrm{l}$ Taq polymerase, $1.2 \mu \mathrm{MgCl}_{2}$ solution, 1 $\mu$ template cDNA, and $\mathrm{ddH}_{2} \mathrm{O}$ to a final volume of 20 $\mu$ l. The PCR cycles used were: $94^{\circ} \mathrm{C}$ for $30 \mathrm{~s}$, followed by $55^{\circ} \mathrm{C}$ for $30 \mathrm{~s}$ and $72^{\circ} \mathrm{C}$ for $30 \mathrm{~s}$. The last extension was at $72^{\circ} \mathrm{C}$ for $10 \mathrm{~min}$. Samples were analyzed by $1 \%$ agarose gel electrophoresis. The expression level of the
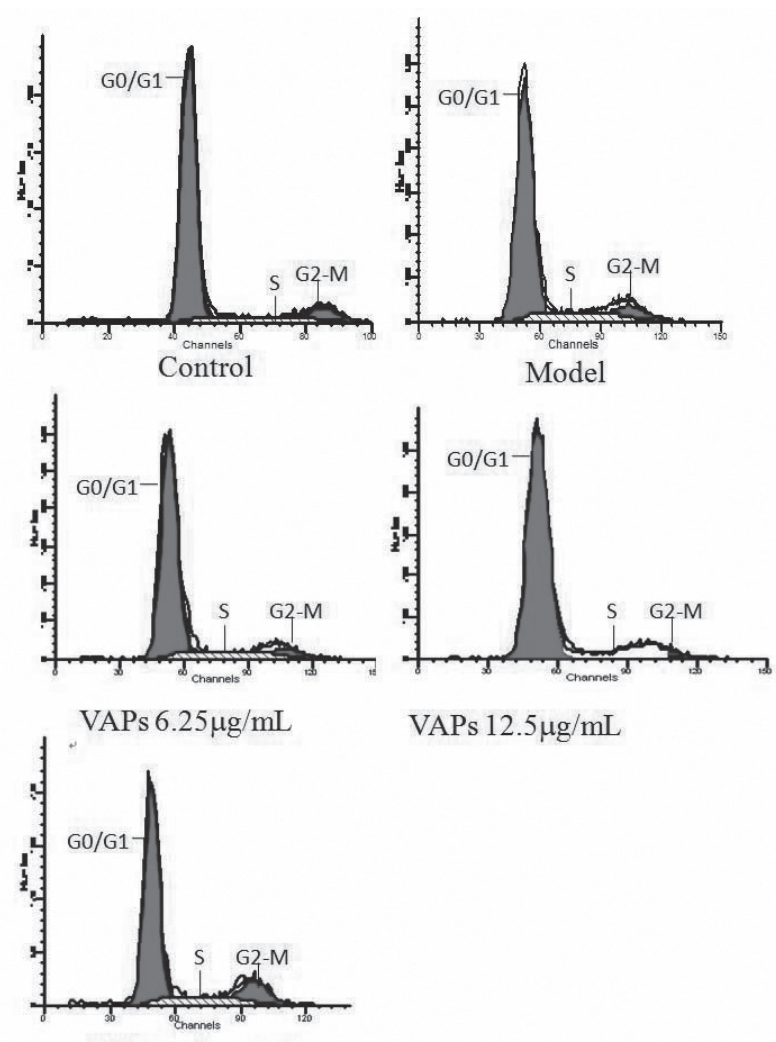

VAPs $12.5 \mu \mathrm{g} / \mathrm{mL}$

VAPs $25.0 \mu \mathrm{g} / \mathrm{mL}$

Figure 1. Effects of VAPs on the cell cycle of OCs Flow cytometry showed that the VAPs did not exhibit any obvious regulatory activity on the OC cell cycle. 
Table 2. Effects of VAPs on the cell cycle of OCs $(n=3)$

\begin{tabular}{llll}
\hline Group & $\mathrm{G}_{0} / \mathrm{G}_{1}(\%)$ & $\mathrm{G}_{2}-\mathrm{M}(\%)$ & $\mathrm{S}(\%)$ \\
\hline Control & $76.41 \pm 2.40$ & $14.99 \pm 2.39$ & $8.60 \pm 1.76$ \\
Model & $66.71 \pm 2.12^{* *}$ & $19.96 \pm 1.53^{*}$ & $13.33 \pm 2.34^{*}$ \\
$6.25 \mu \mathrm{g} / \mathrm{mL}$ VAPs & $64.93 \pm 1.46$ & $20.97 \pm 2.07$ & $14.10 \pm 2.48$ \\
$12.5 \mu \mathrm{g} / \mathrm{mL}$ VAPs & $64.90 \pm 2.90$ & $19.70 \pm 3.32$ & $15.39 \pm 2.92$ \\
$25.0 \mu \mathrm{g} / \mathrm{mL}$ VAPs & $65.05 \pm 4.95$ & $20.30 \pm 3.67$ & $14.65 \pm 1.45$ \\
\hline
\end{tabular}

Note: ${ }^{*} P<0.05,{ }^{* *} P<0.01$ vs. control

various genes was analyzed on an imaging system with $\beta$-actin used as a reference.

Detection of early apoptosis in chondrocytes. Flow cytometry analysis was used to determine the level of apoptosis, $5 \times 10^{4} / \mathrm{mL}$ chondrocytes from each group were seeded in 6-well plates, with $2 \mathrm{~mL}$ of suspension in every well. After cell adherence, $1 \mathrm{~mL}$ of VAPs was added to each flask and the cells were cultured for $48 \mathrm{~h}$. The cells were digested with $0.25 \%$ trypsin and collected for annexin V-PI double staining and incubated for 10 $\min$ at $15^{\circ} \mathrm{C}$ in the dark. The data were analyzed with Becton Dickinson CELLQuest software.

Statistical and image analysis. The EXCEL statistical software, ANOVA, and Student's $t$-test were used for statistical analysis. Immunohistochemical staining was analyzed using Image-Pro image analysis software. In accordance with the 5-point sampling method, the images of 4 sections in each experimental group under the same magnification were randomly collected for gray-scale analysis. The positive target area was calculated and divided by the total area of vision to obtain the average area density of positive action. Image and quantitative analyses were conducted for mRNA expression by using the Tanon GIS-2020 gel imaging system.

\section{RESULTS}

\section{Effect of VAPs on proliferation of OCs}

The MT'T test results are shown in Table 1. Compared with the control group, the model group exhibited significantly higher proliferation of OCs, indicating that the newly isolated OCs retained their characteristics after phenotype determination. The VAPs slightly accelerated the cell proliferation of every group, whereas no significant difference was detected, suggesting that VAPs have a limited effect in promoting cell proliferation.

\section{Effect of VAPs on the OC cell cycle}

Table 2 and Fig. 1 show that the model group exhibited a slightly lower proportion of $G_{0} / G_{1}$-phase cells

Table 3. Effects of VAPs on early apoptosis of OCs $(n=3)$

\begin{tabular}{lc}
\hline Group & Apoptosis (\%) \\
\hline Control & $4.74 \pm 0.30$ \\
Model & $10.29 \pm 0.39^{* * *}$ \\
$6.25 \mu \mathrm{g} / \mathrm{mL}$ VAPs & $9.08 \pm 0.60^{\#}$ \\
$12.5 \mu \mathrm{g} / \mathrm{mL}$ VAPs & $6.82 \pm 0.56^{\# \#}$ \\
$25.0 \mu \mathrm{g} / \mathrm{mL}$ VAPs & $5.72 \pm 0.43^{\# \#}$ \\
\hline
\end{tabular}

Note: ${ }^{* *} P<0.001$ vs. control; ${ }^{*} P<0.05,{ }^{\#} P<0.001$ vs. model
$(P<0.01)$ and significantly higher proportion of $\mathrm{G}_{2} / \mathrm{M}$ - and S-phase cells $(P<0.05)$ compared to the control group. However, no significant difference was observed in cells treated with different concentrations of VAPs as compared with control. Thus, VAPs did not play any obvious regulatory role on the $\mathrm{OC}$ cell cycle. This finding was consistent with the results of the proliferation test.

\section{Effect of VAPs on early apoptosis of chondrocytes}

As shown in Table 3 and Fig. 2, the model group exhibited a significantly higher proportion of early apoptotic cells $(P<0.001)$ compared to the control group. The VAPs significantly reduced the proportion of early apoptotic cells in a dose-dependent manner, suggesting that they inhibit early apoptosis of chondrocytes and confer a protective effect on chondrocytes.

\section{Effect of VAPs on MMP-1, MMP-3, MMP-13, TIMP-1, and collagen $I$ and $X$ mRNA expression in chondrocytes}

VAPs inhibited the expression of collagen I and $\mathrm{X}$ mRNA, and lowered the abnormal expression of MMP-1 and MMP-13 mRNA (Fig. 3). They had no marked effect on the MMP-3 and TIMP-1 mRNA levels. These results suggest that VAPs can inhibit the abnormally high expression of collagen and thereby
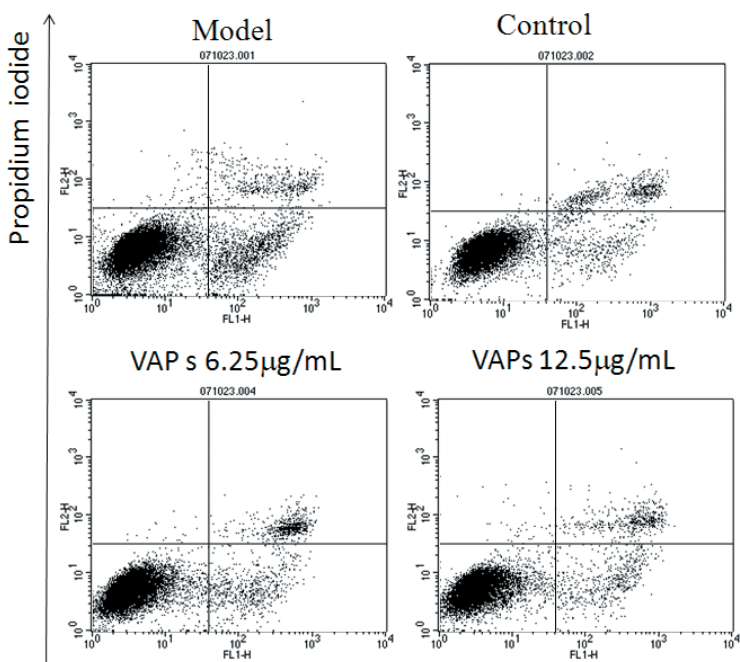

VAPs $12.5 \mu \mathrm{g} / \mathrm{mL}$
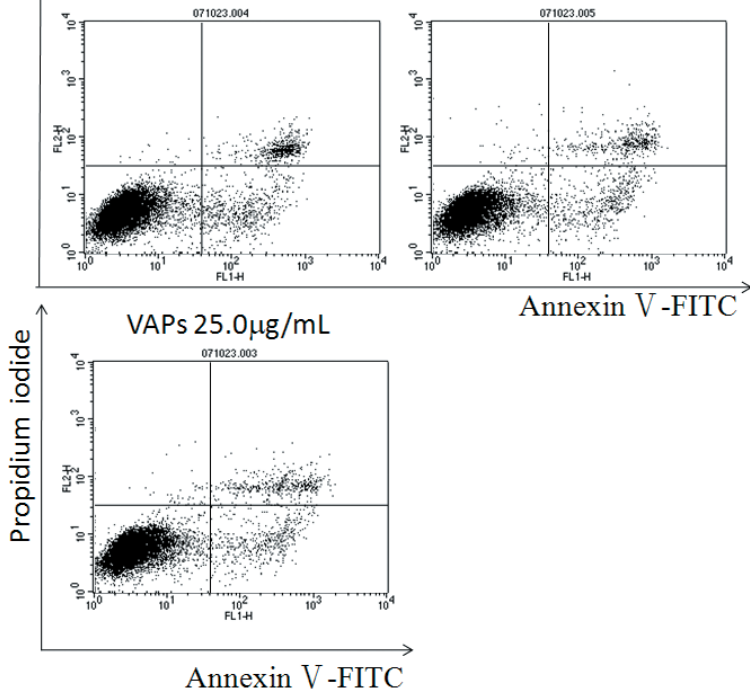

Annexin V-FITC

Figure 2. Effects of VAPs on the early apoptosis in chondrocytes FACS analysis was performed for $5 \times 10^{4}$ cells in each sample by double staining with Annexin $\mathrm{V}$ and propidium iodide after culturing the cells for $48 \mathrm{~h}$. The lower left quadrant shows viable cells, the lower right quadrant shows early apoptotic cells, the upper right quadrant shows late apoptotic cells, and the upper left quadrant shows necrotic cells. 

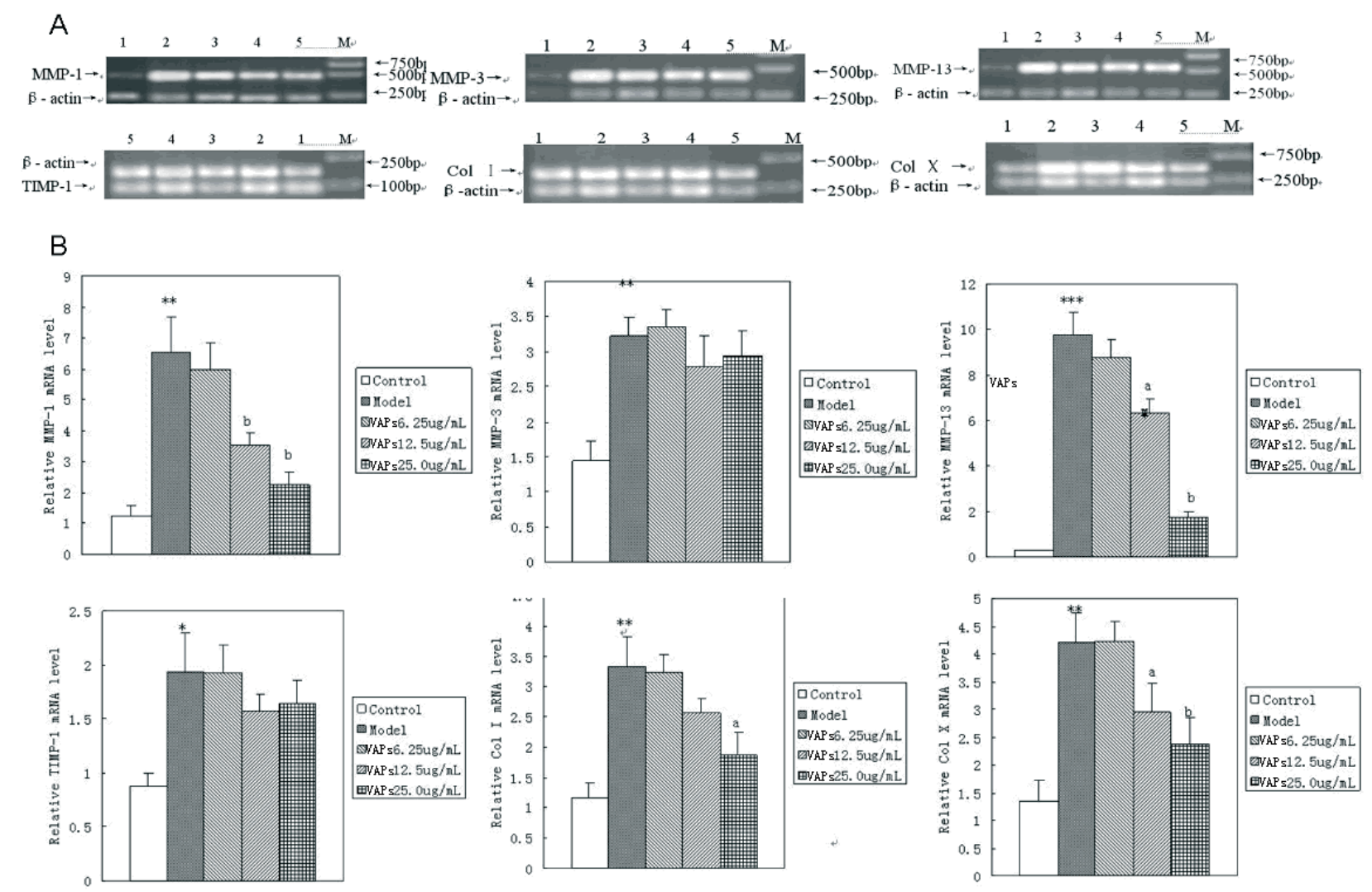

Figure 3. Effects of VAPs on MMP-1, MMP-3, MMP-13, TIMP-1, and collagen I and X mRNA expression by chondrocytes

VAPs inhibited the expression of collagen I and X mRNA as well as the abnormal expression of MMP-1 and MMP-13 mRNA. They had no significant effect on MMP-3 and TIMP-1 mRNA levels. The results were quantified based on three experiments and are presented as means \pm S.D. ${ }^{* *} P<0.01$ vs. control; ${ }^{a} P<0.05$, and ${ }^{b} P<0.01$ vs. model group.

$\mathrm{I}$
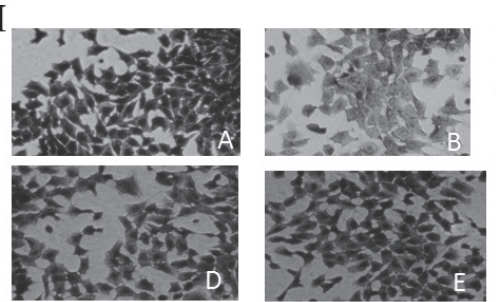

II
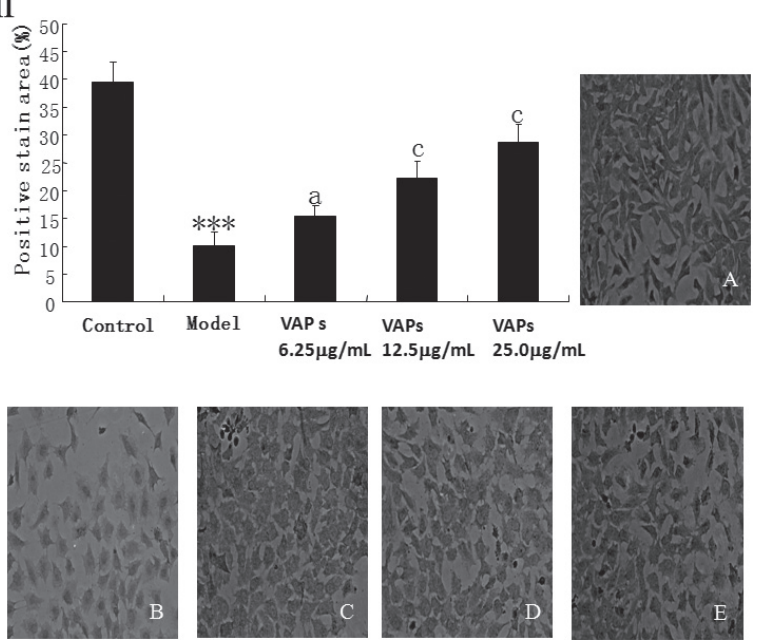

contribute to the retention of the chondrocyte phenotype. In addition, VAPs can simultaneously lower the high expression of some degradation enzymes, thereby partially inhibiting the excessive degradation of the cartilage matrix.

\section{Effect of VAPs on the OC phenotype}

Under a light microscope, chondrocytes from the control group were strongly stained with toluidine blue, while those from the model group were unstained. The toluidine blue staining deepened with an increase in the VAPs concentration (Fig. 4I), indicating that the GAG levels in the chondrocytes gradually

Figure 4. Effects of VAPs on the OC phenotype

Collagen II staining was observed under inverted microscope. (I) Toluidine blue staining of cartilage $(200 \times)$ under a light microscope. Chondrocytes from the control group were found to be strongly stained with toluidine blue, while those from the model group were unstained. The GAG level in the chondrocytes gradually increased with an increasing concentration of VAP treatment. (II) Immunohistochemical staining for collagen type II in OCs $(200 \times)$. Immunohistochemical staining for collagen type II in chondrocytes showed that the staining was weakly positive, and for the model group the area of positive staining was significantly smaller than of the control group. After treatment with VAPs at different concentrations, the immunohistochemical staining for collagen II gradually intensified, indicating that the collagen II level in the cells had recovered. ${ }^{* * *} P<0.001$ vs. control; a $P<0.05$, $c P<0.001$ vs. model group. 
Table 4. Primer sequences used in the study

\begin{tabular}{|c|c|c|}
\hline Gene & Length & Sequence of primers \\
\hline \multirow[t]{2}{*}{ MMP-1 } & $322 \mathrm{bp}$ & Sense 5'-TCA GTT CGT CCT CAC TCC AG-3' \\
\hline & & Antisense 5'-TTG GTC CAC CTG TCA TCT TC-3' \\
\hline \multirow[t]{2}{*}{ MMP-3 } & $363 \mathrm{bp}$ & Sense 5'-GCC AAG AGA TGC TGT TGA TG-3' \\
\hline & & Antisense 5'-AGG TCT GTG AAG GCG TTG TA-3' \\
\hline \multirow[t]{2}{*}{ MMP-13 } & $527 \mathrm{bp}$ & Sense 5'-TTC GCT TAG AGG TGA CAG G-3' \\
\hline & & Antisense 5'-ACT CTT GCC GGT GTA GGT GT-3' \\
\hline \multirow[t]{2}{*}{ TIMP-1 } & $326 \mathrm{bp}$ & Sense 5'-GCA ACT CCG ACC TTG TCA TC-3' \\
\hline & & Antisense 5'- AGC GTA GGT CTT GGT GAA GC-3' \\
\hline \multirow[t]{2}{*}{ Collagen I } & $312 \mathrm{bp}$ & Sense 5'-GAT GGC CTG AAG CTC AA-3' \\
\hline & & Antisense 5'-GGT TTG TTG AAG AGG CTG-3' \\
\hline \multirow[t]{2}{*}{ Collagen X } & $306 \mathrm{bp}$ & Sense 5'-CCA GTG AGA GGA GAA CAA GG-3' \\
\hline & & Antisense 5'-TGG CAC AGA AAT GCC AGC TG-3' \\
\hline \multirow[t]{2}{*}{$\beta$-Actin } & $227 \mathrm{bp}$ & Sense 5'-GCC ATC CTG CGT CTG GAC CTG GCT-3' \\
\hline & & Antisense 5'-GTG ATG ACC TGG CCG TCA GGC AGC-3' \\
\hline
\end{tabular}

collagens I, III, and X as well as decreased expression of collagen II (Guo et al., 2003). Our results are in agreement with those previous results. Therefore, although the OCs were in an active state of proliferation, phenotypic changes caused their differentiation toward fibrochondrocytes or hypertrophic chondrocytes rather than normal cartilage tissue. Due to the constant stimulation by damaging factors and abnormal results caused by compensatory restoration coupled with enhanced catabolism, the cartilage structure was gradually destroyed, and osteoarthritis became more severe. VAPs can increase the GAG and collagen II levels in chondrocytes, and reduce the level of collagen $\mathrm{I}$ and $\mathrm{X}$ mRNA. Thus, VAPs may repair the early damage of cartilage and delay the progression of osteoarthritis. increased with the increasing concentration of VAPs. These results suggested that although VAPs do not seem to have a clear regulatory role in the proliferation of chondrocytes, they promote the maintenance of the normal phenotype of chondrocytes.

The immunohistochemical staining for collagen type II in the chondrocytes is shown in Fig. 4II. In the model group, the staining was weakly positive, and the area of positive staining was markedly smaller than that of the control group. After treatment with VAPs at different concentrations, the immunohistochemical staining for collagen II gradually intensified, indicating that the collagen II level in the cells had recovered. Collagen type II is the characteristic collagen of hyaline cartilage. These results suggest that VAPs assist in maintaining normal collagen secretion of chondrocytes as well as a normal phenotype.

\section{DISCUSSION}

Osteoarthritic chondrocytes (OCs) play a major role in osteoarthritis, which is a common chronic joint disease in the elderly that causes significant pain and disability. Previous studies had shown that VAPs can promote the proliferation of normal chondrocytes, but the effects of VAPs on OCs proliferation were not clear. One possibility is that in the active proliferative state, the regulatory factors of OCs dominantly control proliferation, and therefore the OCs are insensitive to VAPs. Alternatively, since the VAPs were dissolved in medium containing $10 \%$ serum in those studies, serum growth factors may have masked the proliferation-promoting effects of VAPs.

Collagen type II is the characteristic matrix component produced by chondrocytes. Collagen types I and III are predominantly secreted by fibroblasts. Collagen $\mathrm{X}$ is produced by hypertrophic chondrocytes (Von Der Mark et al., 1992). Histologically, OCs is characterized by cartilage fibrillation, collagen II degeneration, aggrecan loss, blood vessel invasion, chondrocyte hypertrophy, and cartilage calcification (Gauci et al., 2008). In a previous study, OCs showed phenotypic changes, as indicated by the increased expression of
Since the metabolism and catabolism of normal cartilage matrix are in balance, the structure, form, and function of normal cartilage are maintained. Increased MMP expression can be detected in the early stages of osteoarthritis (Pelletier, 1990). When the increased compensatory synthesis of cartilage matrix and cell proliferation cannot offset the loss of the extracellular matrix due to catabolism, chondrocyte apoptosis occurs as a result of the unstable internal environment, and this is the direct cause for cartilage loss in the intermediate and advanced stages of osteoarthritis. VAPs inhibit the overexpression of some MMPs by chondrocytes, which helps maintain the cartilage matrix metabolic balance and protect cartilage.

Most normal chondrocytes are in the resting period, and the proportion of apoptotic cells is low (Aigner et al., 2001). The increase in the number of apoptotic chondrocytes is the main cause of chondrocyte loss (Kim et al., 2000). An important role of apoptosis in OCs has been demonstrated in both in vitro and in vivo models. However, it should be noted that the relative contribution of apoptotic cell death in the pathogenesis of osteoarthritis is still difficult to assess, due to the chronic nature of the disease. The death receptor, mitochondrial, and endoplasmic reticulum pathways are the major cellular pathways involved in apoptosis (Kim \& Blanco, 2007). In the early stages of osteoarthritis, the ratio of apoptotic chondrocytes increases significantly, suggesting that the apoptotic pathway is initiated in chondrocytes by damaging factors. VAPs can inhibit the increase in the number of early-apoptotic chondrocytes, and therefore may block apoptosis in chondrocytes and protect them from cell death. This study has shown that VAPs have effects on the phenotype, MMP secretion, and apoptosis of chondrocytes, indicating that VAPs can have a substantial therapeutic effect in osteoarthritis.

\section{Acknowledgement}

This work was supported by the National Natural Science Foundation of China, grant No. 30472224, and was supported by the Fundamental Research Foundation of Jilin University, grant No. 201103232. 


\section{REFERENCES}

Aigner T, Hemme Lm, Neureiter D (2001) Apoptotic cell death is not a wide spread phenomenon in no rmalaging and osteoarthritis human articular knee cartilage. J Arthritis Rheum 44: 1304-1312.

Duan Lx (2007) Studies on the chemical structrue of velvet antler polypeptides (cervus Nippon temminck) and its anti-hepatic fibrosis. $D$, Jilin University.

Gauci SI, Golub SB, Tutolo L, Little CB, Sims NA, Lee ER, Mackie EJ, Fosang AJ (2008) Modulating chondrocyte hypertrophy in growth plate and osteoarthritic cartilage. J Musculoskelet Neuronal Interact 8: 308-310.

Guo Y, Zhou Q, Liu P, Wang Y, Fang J, Wang B (1998) The research of pilose antler polypeptides promoting osteoblast precursor cells and chondrocytes proliferation. J Chinese J Biochem Pharmaceutics 19: 74-75.

Guo Q, Tian D, Ao Y (2003) The collagen phenotype of normal and osteoarthritis cartilages. J Chinese J Sports Med 22: 204-209.

Kim HA, Blanco FJ (2007) Cell death and apoptosis in osteoarthritic cartilage. J Curr Drug Targets 8: 333-345.

Kim HA, Lee YJ, Seong SC, Choe KW, Song YW (2000) Apoptotic chondrocyte death in human osteoarthritis. J Rheumatol 27: 455-462.

Kim Y-K, Kim K-S, Chung K-H, Kim J-G, Kim K-S, Lee Y-C, Chang Y-C, Kim C-H (2003) Inhibitory effects of deer antler aquaacupuncture, the pilose antler of Cervus Korean Temminck var. mantchuricus Swinhoe, on type II collagen-induced arthritis in rats. J Int Immunopharmacol 3: 1001-1010.
Kim K-H, K-S, Choi B-J, Chung K-H, Chang Y-C, Lee S-D, Park K-K, Kim H-M, Kim C-H (2005) Anti-bone resorption activity of deer antler aqua-acupunture, the pilose antler of cervus korean TEMMINCK var. mantchuricus Swinhoe (Nokyong) in adjuvantinduced arthritic rats. J Ethnopharmacol 96: 497-506.

Kim KW, Song KH, Lee JM, Kim KS, Kim SI, Moon SK, Kang BS, Kim DS, Chung KH, Chang YC, Kim CH (2008) Effects of TGFbeta1 and extracts from Cervus korean TEMMINCK var. mantchuricus Swinhoe on acute and chronic arthritis in rats. J Ethnopharmacol 118: $280-283$.

Kraan PM, Blaney Davidson EN, Blom A, Berg WB (2009) TGF-beta signaling in chondrocyte terminal differentiation and osteoarthritis: modulation and integration of signaling pathways through receptorSmads. J Osteoarthritis Cartilage 17: 1539-1545.

Liu X, Li X, Zhou J (2005) Experimental study on replicating knee osteoarthritis by modified Hulth's modeling method. J Chinese J Int Trad West Med 25: 1104-1108.

Pelletier JP (1990) Imbalance between the mehanisms of activation and inhibition of metallo-proteases in the early lesions of experimental osteoarthristis. J Atthritis Rheum 33: 364-367.

Qu M, Kang Y (2000) Study on biological characteristics of hypertrophic chondrocytes of damaged articular cartilage. J Chinese I Sports Med 19: 76-81.

Von Der Mark K, Kirsch T, Nerlich A, Kuss A, Weseloh G, Glückert K, Stöss H (1992) Type X collagen synthesis in human osteoarthritic cartilage. indication of chondrocyte hypertrophy. I Arthritis Rheum 35: 806-811. 